\section{Turf Manager Response to Changing Pesticide Regulations}

\author{
Victoria H. Wallace ${ }^{1,2}$ \\ Department of Extension, University of Connecticut, 562 New London \\ Trunpike, Norwich, CT 06360
}

Candace Bartholomew ${ }^{1}$

Department of Extension, University of Connecticut, 1800 Asylum Avenue, West Hartford, CT 06117

\author{
Julie H. Campbell ${ }^{1}$ \\ Department of Plant Science and Landscape Architecture, University of \\ Connecticut, 1376 Storrs Road, Unit 4067, Storrs, CT 06269
}

Additional index words. pesticide ban, turfgrass, school grounds, athletic fields

\begin{abstract}
A mail survey was distributed to school turfgrass managers throughout Connecticut focusing on the differences between turfgrass management practices for kindergarten through eighth-grade (K-8) school grounds before, during, and after a 2010 ban on pesticide use at these facilities. The results indicate that as turf care protocol transitioned from an integrated pest management (IPM) program to new pesticide-free regulatory requirements, school grounds/athletic field managers did not significantly adjust their management programs. The percentage of managers applying pesticides on K-8 grounds decreased, as expected, with the implementation of the new pesticide ban; however, pesticide applications on high school grounds/athletic fields also decreased. Furthermore, it was observed that there had been minimal adoption of minimum risk 25(b) products, the suggested alternative to traditional synthetic pesticides. With respect to other cultural practices, we found that few changes have been made to other cultural practices that would improve turf quality. Budgetary issues facing school grounds/ athletic field managers may have limited their ability to implement potentially costly management practices necessary to offset the loss of pesticides. Educational efforts to promote new management practices have the potential to inform school grounds/athletic field managers about new methods, thereby, potentially increasing adoption.
\end{abstract}

Pesticide usage throughout the United States is coming under increasing scrutiny due to potential environmental and health concerns. Notably, concern about pesticide residue exposure of children at schools has intensified the debate over use of pesticides on school grounds and athletic fields. In particular, some research has indicated that when children come into contact with pesticides on school grounds there is a potential for health risks associated with prolonged pesticide exposure (Alarcon et al., 2005; Gilden et al., 2012). As these perceived concerns have increased in number, states have enacted various regulations to limit or eliminate pesticide exposure at schools. Currently, 40 states have varying levels of school pest management regulations which limit or eliminate pesticide usage on school grounds (Hurley et al., 2014). While regulations vary by state, Connecticut and New York have the most restrictive regulations. In Connecticut, a total ban of pesticides on school grounds

Received for publication 16 Dec. 2015. Accepted for publication $19 \mathrm{Feb} .2016$.

${ }^{1}$ Authors share senior authorship for this manuscript.

${ }^{2}$ Corresponding author. E-mail: victoria.wallace@ uconn.edu. turfgrass managers, as they adapt to new pesticide regulations, several studies have put forth suggested alternative management practices to offset the need for regular, scheduled pesticide use (Bingaman and Christians, 1995; Koppenhöfer and Fuzy, 2008; Liu and Christians, 1997; Miller and Henderson, 2012, 2013). Key recommendations include increased overseeding, cultivation, manual weed pulling, and/or the use of EPA approved minimum risk 25 (b) products.

Given the transition of regulations from a full, calendar-based pesticide program to an IPM program to no pesticide use, Connecticut offers an ideal opportunity to examine how school ground managers adapted to changing pesticide regulations. The intended focus of this paper was to examine the differences between the varying turfgrass management regimes of school grounds managers under no pesticide restrictions, IPM, and pesticide regulations. Our hypothesis was that school ground managers would significantly change management practices as they reduced the amounts of pesticide used in their turf management program. Notably, it was hypothesized that there would be an increase in the use of minimum risk 25(b) products with the implementation of the pesticide ban. Furthermore, although not mandated by the regulations, we examine pesticide usage for 9-12th grade (i.e., high school) school grounds compared with management programs for K-8 school grounds.

\section{Materials and Methods}

To examine school manager maintenance practices, a mail survey was distributed to school grounds managers throughout Connecticut and was administered by the University of Connecticut Extension faculty during the fall of 2012. A list of school grounds managers in Connecticut was developed from various member associations lists (i.e., Connecticut Association of School Business Officials, Connecticut Association of Public School Superintendents, Connecticut Association of Boards of Education, Connecticut Recreation and Parks Association, Connecticut Parks Association, New England Sports Turf Managers Association, Connecticut Schools Building Grounds Association and Connecticut DEEP, Pesticide Management Division). Individual school grounds managers from several towns/cities were consulted to add and/or refine the contact list. Finally, if no contact in a specific city/town could be identified, the city/town clerk's office was requested to provide an appropriate school grounds manager contact. There are 169 cities and towns in Connecticut and a total of 151 managers were identified, most of whom worked for either the Public Works Department, the Parks and Recreation Department or the Board of Education.

The survey of the school grounds managers followed the format described by Salant and Dillman (1994). Contacts from the survey list were sent an initial request for 
participation in a forthcoming survey. The following week managers received a cover letter, survey, and a postage paid return envelope. Two weeks later managers who had not returned the survey were requested again to respond to the survey. A final reminder card followed 2 weeks after the first reminder request. To increase survey participation, school managers attending educational workshops developed by the Connecticut School IPM Coalition were reminded about participation in the survey. If no response had been received after the second reminder card, each nonresponding school manager on the list was contacted by phone to request participation. School grounds managers were told participation in the survey was voluntary and their survey answers would remain confidential. Before the survey was distributed, it was approved by the university internal review board and had been pretested by five managers before the general mailing.

Survey questions focused on school turf, grounds budgets, and pest management practices used during the transition from conventional pesticide use to the pesticide ban. Information about demographic and managerial experience also was requested. The response to the pest management questions were of key importance. These questions asked school grounds managers to identify the top three perceived pest problems on school grounds (open answer), and key pest management practices used on school grounds locations (i.e., athletic fields, parking lots, sidewalks, etc.), as well as incorporation of minimum risk 25(b) products into their management practices after the bans implementation.

A total of 47 completed surveys were returned for a $31 \%$ response rate. According to Kaplowitz et al. (2004) and Shih and Fan (2008), a response rate in this range is similar to other mail surveys. Given the total population of school grounds managers in the state is $\approx 151$, our sample response rate of $31 \%$ allowed us to feel confident that our inferences from the results provide an adequate representation of the management practices of Connecticut school grounds managers. However, the sample size is small in absolute quantity which could potentially limit the findings that have occurred if a larger sample could have obtained. To form an opinion about the representativeness of Connecticut town population estimates, we determined our sample was one from a slightly more urbanized area (sample population density $=1453$; average town population density = 738 from Census Bureau estimates). However, this does not invalidate our findings, but is a slight limitation of the study.

Given the questions of interest were frequencies; we used a chi square test to test for distributional differences between the variables of interest. Statistical testing is appropriate for determining whether differences are present; however, a more intuitive hands-on approach is also viable to evaluate the overall picture over time. We, therefore, used the chi square test, along with an observational approach to understand how
Connecticut school grounds managers have managed with changing pesticide regulations over time.

\section{Results and Discussion}

In an attempt to understand how changing pesticide regulations have impacted school ground management practices, it is critical to identify the most important pest problems faced by school managers. Of pest problems referenced, crabgrass was perceived to be the most frequently recognized pest problem identified by school ground managers regardless of the type of regulation in effect (Table 1). Other specific problems mentioned were grubs and broad-leaved weeds, especially dandelions.

Management practices at $K-8$ facilities. As regulations change, school grounds managers must be proactive in how they manage their turfgrass areas. However, as evident in $\mathrm{Ta}$ ble 2, managers do not appear to be changing their management practices. Other than the decrease in pesticide use, there were no significant management changes moving from conventional (calendar) management to IPM to "no" pesticide use. With respect to pesticide applications, it was observed that $54 \%$ of the school grounds managers indicated that pesticides were used before any regulations and that use percentage dropped to $11 \%$ after the ban was imposed. The $11 \%$ may be the result of pesticide application permits that are offered by DEEP in special cases.

Since the pesticide ban, cultural management practices recommended to help ease the transition away from pesticide dependency (i.e., overseeding and hand pulling of weeds) have not significantly changed. Before the pesticide ban going into effect, $62 \%$ of managers used overseeding as a standard cultural practice in their turf care management regime. Under the required IPM program, the percentage of overseeding used by the grounds manager increased, although not significantly, to $78 \%$. However, with the pesticide ban in place, only $60 \%$ of managers overseed their athletic fields. A lack of an increase in overseeding practices may be due to a number of reasons. Grounds managers may not be current with sports turf research that favor overseeding as a standard recommendation to improve turf quality in the absence of chemical use (Henderson et al., 2013). There may be budget constraints on towns preventing the purchase of the increased quantities of seed needed each year to maintain field quality. There also could be a lack of effective townowned overseeding equipment or limited man power to adequately spread the recommended high rate of seed on athletic fields. Finally, K-8 school grounds are not a budget priority compared with the high school grounds.

Table 1. Top problems described by school ground managers under varying pesticide regulations as found in the 2012 school grounds/athletic field manager survey conducted by the University of Connecticut.

\begin{tabular}{lccc}
\hline & \multicolumn{3}{c}{ Pesticide regulation $^{2}$} \\
\cline { 2 - 4 } Problem & \multicolumn{3}{c}{ Percentage of managers reporting the problem } \\
\cline { 2 - 4 } Conventional (\%) & IPM (\%) & No pesticide (\%) \\
\hline Dandelion & 55 & 38 & 44 \\
Crabgrass & 87 & 84 & 80 \\
Grubs & 74 & 70 & 66 \\
Other & 53 & 78 & 71 \\
\hline
\end{tabular}

IPM $=$ integrated pest management.

${ }^{z}$ No statistical differences were found for any of the conventional vs. IPM comparisons at either the 0.1 , 0.05 , or 0.01 level.

Table 2. Management practices used in kindergarten through eighth-grade school grounds under different pesticide regulations as found in the 2012 school grounds/athletic field manager survey conducted by the University of Connecticut.

\begin{tabular}{|c|c|c|c|}
\hline \multirow[b]{3}{*}{ Management practice } & \multicolumn{3}{|c|}{ Pesticide regulation } \\
\hline & \multicolumn{3}{|c|}{ Percentage of managers using the practice } \\
\hline & Conventional ${ }^{\mathrm{z}}(\%)$ & IPM $(\%)$ & No pesticide $(\%)$ \\
\hline Pest monitoring (scouting) & 62 & 65 & 63 \\
\hline Sharpen mower blades regularly & 76 & 81 & 71 \\
\hline Leave clippings after mowing & 76 & 73 & 74 \\
\hline Over seeding & 62 & 78 & 60 \\
\hline Hand pulling weeds & 27 & 35 & 37 \\
\hline Pesticide applications & $54 \mathrm{a}$ & $35 \mathrm{ab}$ & $11 \mathrm{~b}$ \\
\hline $\begin{array}{l}\text { Mowing at proper height and } \\
\text { frequency for the season }\end{array}$ & 78 & 81 & 69 \\
\hline Biological pest management & 5 & 3 & 3 \\
\hline Growing degree day prediction & 11 & 8 & 6 \\
\hline Top dressing turf & 32 & 43 & 37 \\
\hline Irrigation & 43 & 51 & 46 \\
\hline Torching weeds & 3 & 8 & 6 \\
\hline Conduct soil tests & 57 & 59 & 57 \\
\hline Aeration & 65 & 73 & 63 \\
\hline
\end{tabular}

IPM $=$ integrated pest management.

${ }^{\mathrm{z}}$ Different letters indicate a statistical difference from other variables located in the same row at the 0.1 level. 
With respect to management practices used to improve turf quality, hand pulling of weeds was used only by $27 \%$ of grounds managers as part of a conventionally managed program. The percentage of use for this practice was increased to $35 \%$ and $37 \%$ with the incorporation of IPM practices and a pesticide ban, respectively. Even with a total pesticide ban, with limited means of weed control, few managers used and implemented this strategy. This is most likely due in part to the increased labor cost associated with this intensive management activity and limited staff.

Management practices at high school facilities. Given the limited resources of many school ground managers, it was hypothesized that regulations impacting K-8 grounds would also impact decisions for grounds managers that maintained high school grounds. As noted in Table 3, management practices across regulations were not significantly different except for the manager's pesticide applications. As the level of pesticide applications decreased on K-8 grounds, pesticide use on high school grounds also experienced a decrease. Before the pesticide ban taking effect, $70 \%$ of grounds managers indicated pesticide applications were a regular part of their management program. However, after the full pesticide ban was implemented the percentage of pesticide use decreased to only $29 \%$. Currently, the Connecticut legislature continues to debate the need for a pesticide ban that would officially alter current practices and ban pesticide use on high school grounds (Connecticut General Assembly, 2014). Recent language was introduced at the budget implementer level that banned pesticide use on municipal playgrounds and altered the definition of a pesticide (Connecticut General Assembly, 2015). However, within many school districts, the K-8 school ground ban largely altered or eliminated pesticide usage on high school grounds due to either: 1) concerns that K-8 students also come into contact with high school fields in some recreational capacity or 2) reduced pesticide use on high school properties simplified the turf care programs throughout a district by only having to have one plan for K-12. Many districts that had dual use junior high and senior high school fields were required to maintain a pesticide ban on those school fields as well.

Location of pesticide and pesticide alternative applications. Table 4 indicates that herbicides were the primary pesticide used by school grounds managers. Under the preregulated, conventional and IPM regimes, high school athletic fields, and grounds were most likely to receive a pesticide application compared with K-8 school fields and grounds. This same consistency of use also held true for fungicide and insecticide use. Throughout nonathletic high school ground properties there was a diversity in the types of pesticides used, although the type of pesticide dictated where it was used. In general, herbicides were used on all school grounds properties; however, on nonathletic field areas fungicides and insecticides were not consistently used and not used at all on ancillary areas such as parking lots, sidewalks at K-8 or high school grounds.

With respect to differences noted, as the IPM regulations went into effect, there were no statistical differences between school properties for both K-8 and high school grounds. From an institution perspective, we do see that under an IPM program, compared with a conventional program, the percentage of managers using pesticides in each location decreased, as indicated by the lower percentages associated with IPM (compared with conventional) for both K-8 and high schools. This would provide

Table 3. Management practices used in high school grounds under different pesticide regulations as found in the 2012 school grounds/athletic field manager survey conducted by the University of Connecticut.

\begin{tabular}{lccc}
\hline & \multicolumn{3}{c}{ Pesticide regulation $^{z}$} \\
\cline { 2 - 4 } Management practice & \multicolumn{2}{c}{ Percentage of managers using the practice } \\
\cline { 2 - 4 } Pest monitoring (scouting) & 59 & IPM (\%) & No pesticide (\%) \\
Sharpen mower blades regularly & 76 & 68 & 71 \\
Leave clippings after mowing & 76 & 78 & 71 \\
Over seeding & 78 & 73 & 80 \\
Hand pulling weeds & 30 & 36 & 40 \\
Pesticide applications & 70 a & 51 ab & 29 b \\
Mowing at proper height and frequency & 78 & 81 & 77 \\
$\quad$ for the season & & & 3 \\
Biological pest management & 8 & 14 & 14 \\
Growing degree day prediction & 11 & 51 & 51 \\
Top dressing turf & 38 & 70 & 71 \\
Irrigation & 65 & 5 & 60 \\
Torching weeds & 3 & 65 & 77 \\
Conduct soil tests & 57 & 81 & \\
Aeration & 78 & &
\end{tabular}

IPM $=$ integrated pest management.

${ }^{2}$ Different letters indicate a statistical difference from other variables located in the same row at the 0.1 level or less.

Table 4. Changing pesticide usage by location across pesticide regulations at the kindergarten through eighth-grade (K-8) and high school level as found in the 2012 school grounds/athletic field manager survey conducted by the University of Connecticut. ${ }^{2}$

\begin{tabular}{|c|c|c|c|c|c|c|}
\hline \multirow[b]{3}{*}{ Pesticide usage } & \multicolumn{6}{|c|}{ Percentage of managers using the practice } \\
\hline & \multicolumn{3}{|c|}{ Grades K-8 } & \multicolumn{3}{|c|}{ High school } \\
\hline & $\begin{array}{c}\text { Conventional } \\
(\%)\end{array}$ & $\begin{array}{l}\text { IPM } \\
(\%)\end{array}$ & Difference ${ }^{y}$ & $\begin{array}{c}\text { Conventional } \\
(\%)\end{array}$ & $\begin{array}{l}\text { IPM } \\
(\%)\end{array}$ & Difference $^{y}$ \\
\hline \multicolumn{7}{|l|}{ Herbicide use } \\
\hline Athletic fields & 68 & 45 & & 91 & 82 & \\
\hline Parking lots & 45 & 32 & & 50 & 36 & \\
\hline Sidewalks & 50 & 32 & & 55 & 41 & \\
\hline Common grounds & 36 & 27 & & 55 & 41 & \\
\hline School landscape beds & 45 & 32 & & 50 & 36 & \\
\hline Trees/shrubs on school grounds & 14 & 5 & & 23 & 9 & \\
\hline \multicolumn{7}{|l|}{ Fungicide use } \\
\hline Athletic fields & 9 & 5 & & 32 & 27 & \\
\hline Parking lots & 0 & 0 & & 0 & 0 & \\
\hline Sidewalks & 0 & 0 & & 0 & 0 & \\
\hline Common grounds & 5 & 18 & & 14 & 9 & \\
\hline School landscape beds & 5 & 0 & & 9 & 50 & \\
\hline Trees/shrubs on school grounds & 5 & 0 & & 5 & 0 & \\
\hline \multicolumn{7}{|l|}{ Insecticide use } \\
\hline Athletic fields & 50 & 36 & & 82 & 82 & \\
\hline Parking lots & 0 & 0 & & 0 & 0 & \\
\hline Sidewalks & 5 & 0 & & 0 & 0 & \\
\hline Common grounds & 18 & 0 & & 32 & 18 & \\
\hline School landscape beds & 14 & 5 & & 18 & 14 & \\
\hline Trees/shrubs on school grounds & 23 & 9 & & 27 & 18 & \\
\hline
\end{tabular}
IPM $=$ integrated pest management.

${ }^{z}$ No column is given for no pesticide ban as the ban would preclude use of pesticides (State of Connecticut, 2005).

${ }^{y}$ No statistical differences were found for any of the conventional vs. IPM comparisons at either the 0.1 , 0.05 , or 0.01 level. 
Table 5. Usage of 25(b) products after the pesticide ban as found in the 2012 school grounds/athletic field manager survey conducted by the University of Connecticut.

\begin{tabular}{lcc}
\hline & \multicolumn{2}{c}{ Percentage of managers using the practice } \\
\cline { 2 - 3 } & \multicolumn{2}{c}{ 25(b) Product use ${ }^{z, y}$} \\
\cline { 2 - 3 } Location of product usage & $\begin{array}{c}\text { Grades kindergarten through } \\
\text { eighth-grade }(\mathrm{K}-8)(\%)\end{array}$ & High school (\%) \\
\hline Athletic fields & 5 & 5 \\
Parking lots & 5 & 5 \\
Sidewalks & 8 & 5 \\
Common grounds & 10 & 3 \\
School landscape beds & 3 & 0 \\
Trees/shrubs on school grounds & 0 & 5 \\
\hline
\end{tabular}

${ }^{2} 25$ (b) products could include clove oil, cinnamon oil, acetic acid, etc. (United States Environmental Protection Agency, 2015).

${ }^{y}$ No statistical differences were found for any of the grades K-8 vs. high school comparisons at either the $0.1,0.05$, or 0.01 level.

that have already transitioned to a pesticide-free management strategy, we also observe that while there is a slight increase in use of these products compared with their use on $\mathrm{K}-8$ properties, the overall use of minimum risk $25(\mathrm{~b})$ is of a very low percentage. This could be because currently very little scientific data on the effectiveness of these products exists. Researchers at the University of Connecticut are studying the timing, effectiveness, and sensitivity of many of the products on this list to give managers a better understanding of these products.

\section{Conclusions}

As more states attempt to regulate pesticides on school properties, it is essential to understand how school ground managers are adapting their management protocols to meet new regulations and redefine acceptable management standards. Given the myriad of studies that have linked playing surface quality to sports injuries (Chomiak et al., 2000; Harper et al., 1984; Orchard, 2002) a failure to adjust turf care practices to improve turf quality and provide safe playing surfaces could be detrimental to children's health. This study examined how school ground managers are attempting to adapt and realign their management practices to progressively distinct and different turf management regimes driven by mandated regulations. The results indicate that as turf care protocol transitioned from an IPM program to new pesticide-free regulatory requirements, school ground managers have not significantly adjusted their management programs. The percentage of managers applying pesticides on K-8 grounds decreased, as expected, with the implementation of the new pesticide ban; however, pesticide applications on high school grounds have also decreased. Furthermore, it was observed that there has been minimal uptake of minimum risk 25(b) products, the suggested alternative to traditional synthetic pesticides.

The results observed from this study indicate that while school ground managers have made substantial changes to their pesticide application practices, grounds managers have been reluctant to implement other cultural practices that also would improve turf quality. The reason for this is largely unknown, but our hypothesis is that school ground managers are facing budgetary issues that have often drastically limited their ability to implement potentially costly management practices and increase labor requirements necessary to improve turfgrass quality and offset the loss of pesticides. It should be noted that at the time of the enforcement of the new pesticide regulations, many school districts and municipalities in Connecticut were in step with national trends and forced to reduce their overall maintenance budgets to adjust to the declining nation-wide economic distress. Also, the true impact of the ban was not realized until the 2 nd year after the ban was implemented. To date, many Connecticut districts still have yet to see improvements in their maintenance budgets, which causes school managers to constantly struggle to adequately meet the mandated challenges imposed on them with the 2010 pesticide regulations. For instance, hand pulling of weeds would require an exponential increase in labor expense, and overseeding athletic fields at rates that would improve turf density would require a substantial increase in the volume of grass seed required to be purchased. Many districts chose to or had no choice but to maintain a minimum level of care with the deficit in funding support.

With respect to implications of this research, it is clear that school grounds manager adoption of new management practices is lagging. Little can be done about budgetary restrictions that impact product purchases; however, efforts to educate and offer support to municipalities can be achieved. As noted by Bartholomew et al. (2015), educational workshops can increase perceived quality of fields, which is most likely the result of adoption of new management practices. However, more research is needed to definitively determine the reason why managers are not adopting new management practices.

\section{Literature Cited}

Alarcon, W.A., G.M. Calvert, J.M. Blondell, L.N Mehler, J. Sievert, M. Propeck, D.S. Tibbetts, A. Becker, M. Lackovic, S.B. Soileau, R. Das, J. Beckman, D.P. Male, C.L. Thomsen, and M. Stanbury. 2005. Acute illnesses associated with pesticide exposure at schools. JAMA 294:455-465.
Bartholomew, C., B.L. Campbell, and V. Wallace. 2015. Factors affecting athletic field quality after pesticide bans: The case of Connecticut. HortScience 50:99-103.

Bingaman, B.R. and N.E. Christians. 1995. Greenhouse screening of corn gluten meal as a natural control product for broadleaf and grass weeds. HortScience 30:1256-1259.

Chomiak, J., A. Junge, L. Peterson, and J. Dvorak. 2000. Severe injuries in football players. Amer. J. Sports Med. 28:S58-S68.

Connecticut General Assembly. 2014. 14 July 2015. <http://www.cga.ct.gov/asp/cgabillstatus/ cgabillstatus.asp?selBillType=Bill\&bill_num= SB00046\&which_year $=2014>$.

Connecticut General Assembly. 2015. 14 July 2015. <https://www.cga.ct.gov/2015/fc/ 2015HB-06897-R000184-FC.htm>.

Gilden, R., E. Friedmann, B. Sattler, K. Squibb, and K. McPhaul. 2012. Potential health effects related to pesticide use on athletic fields. Public Health Nursing 29:198-207.

Harper, J.C., C.A. Morehouse, D.V. Waddington, and W.E. Buckley. 1984. Turf management, athletic field conditions, and injuries in high school football. Progress Report 384. Pennsylvania State University, College of Agriculture, Agriculture Experiment Station, University Park, PA.

Henderson, J., V. Wallace, and J. Campbell. 2013. Best management practices for pesticide free cool season athletic fields. Publication by UConn Turfgrass. 15 July 2015. <http://www.turf.uconn.edu/pdf/ research/factsheets/OrganicFields_BMP_2013. pdf?llr=kaiit7cab\&oeidk=a07e81i48ky01bfed07\& oseq $=\mathrm{a} 017 \mathrm{dfxgjiuci}>$.

Hurley, J.A., T.A. Green, D.H. Gouge, Z.T Bruns, T. Stock, L. Braband, K. Murray, C. Westinghouse, S.T. Ratcliffe, D. Pehlman, and L. Crane. 2014. Regulating pesticide use in United States schools. American Entomologist 60(2): 105-114.

Kaplowitz, M.D., T.D. Hadlock, and R. Levine. 2004. A comparison of web and mail survey response rates. Public Opin. Q. 68:94-101.

Koppenhöfer, A.M. and E.M. Fuzy. 2008. Attraction of four entomopathogenic nematodes to four white grub species. J. Invertebr. Pathol. 99:227-234.

Liu, D.L. and N.E. Christians. 1997. Inhibitory activity of corn gluten hydrolysate on monocotyledonous and dicotyledonous species. HortScience 32:243-245.

Miller, N.A. and J. Henderson. 2012. Organic management practices on athletic fields: Part 1. The effects on color, quality, cover, and weed populations. Crop Sci. 52:890-903.

Miller, N.A. and J.J. Henderson. 2013. Organic management practices on athletic fields: Part 2: The effects on playing surface characteristics and soil physical properties. Crop Sci. 53:637-646.

Orchard, J. 2002. Is there a relationship between ground and climatic conditions and injuries in football? Sports Med. 32:419-432.

Salant, P. and D.A. Dillman. 1994. How to conduct your own survey. John Wiley \& Sons, Inc., New York, NY.

Shih, T. and X. Fan. 2008. Comparing response rates from web and mail surveys: A metaanalysis. Field Methods 20:249-271.

State of Connecticut. 2005. Public Act 5-252. 15 July 2015. <http://www.cga.ct.gov/2005/act/ pa/2005pa-00252-r00sb-00916-pa.htm>.

United States Environmental Protection Agency. 2015. Inert ingredients eligible for FIFRA 25(b) pesticide products. $17 \mathrm{Feb} .2016 .<\mathrm{http} / / /$ www.epa.gov/sites/production/files/2015-01/ documents/section25b_inerts.pdf $>$. 